\title{
New vaccines, drugs revitalize tuberculosis research
}

In the lobby of the offices of the Aeras Global TB Vaccine Foundation in Bethesda, Maryland, the walls are decorated with posters from the 1930s that warn of tuberculosis (TB). In those days, the standard preventive agent was the Bacille Calmette-Guérin (BCG) vaccine, only effective ๖ against only some kinds of childhood TB. It's still the only available vaccine-but not for long.

After decades of stagnation in TB research, there arefour vaccines in trials, new diagnostic techniques and about seven new drugs on the horizon.

"Working in TB now is a bit of a candy shop," says Peter Small, who heads the TB program at the Bill \& Melinda Gates Foundation, which is credited with revitalizing the field. "There is great science and huge need," he says.

A third of the world's population has the latent form of TB (in which bugs take up residence in the lungs), but these people don't display symptoms. In those with compromised immune systems, such as HIV-positive individuals, the quiescent bacteria begin actively multiplying. There are 9 million new cases of TB and 2 million deaths each year, many of them in sub-Saharan Africa. Some regions such as Eastern Europe have shown a troubling rise in multidrug-resistant disease.

The standard treatment is a course of four antibiotics for two months followed by two of those for another four months. None of the drugs are ideal, researchers say, because they take too long to kill the bacteria; the strongest of these, rifampin, speeds up the body's breakdown of HIV protease inhibitors, rendering them ineffective.

"We badly need new technologies," says Christopher Dye, head of TB Monitoring and Evaluation

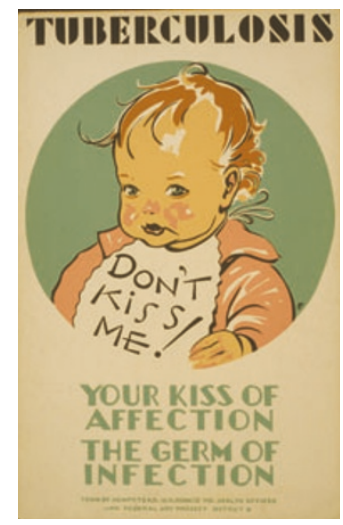

Not much has changed in tuberculosis treatment since this 1930 s poster was made. at the World Health Organization. "We need new drugs, we need new vaccines.”

The darling of the TB community is Tibotec's compound TMC207, which is in phase 2 trials. The compound targets the bugs' ATP synthase, an enzyme they need to store energy, and has proven surprisingly effective in a mouse model (Science 307, 223-227; 2004). "Everyone is amazed at its performance," says Dye.

Public-private partnerships are also ushering in promising compounds by providing market incentive to manufacturers. For instance, the Tuberculosis Trials Consortium is supporting Bayer's moxifloxacin, a broadspectrum antibiotic already on the market for bacterial lung infections. The drug, which researchers hope might snare resistant bugs, is being tested in a multicenter trial of 330 people.

The Global Alliance for TB Drug Development has another candidate, PA-824, which might replace two of the standard drugs (Nature 405, 962-966; 2000). The compound, which could shorten treatment time and promises to fight multidrug-resistant TB, is in safety tests.

On the vaccine front, BCG, once reviled by scientists as weak and limited, has staged a comeback. Adrian Hill at the University of Oxford and others have shown that when used as the first in a double whammy of shots, BCG can help produce a robust immune response (Nat. Med. 10, 1240-1244; 2004). Hill's group combines BCG with MVA85A, a virus decked out with the characteristic antigens of Mycobacterium tuberculosis. Phase 2 trials are underway in South Africa.

The first TB additions to the market may actually be diagnostic techniques. The Geneva-based Foundation for Innovative New Diagnostics is championing at least eight new products. The group aims to cut the time required to detect drug resistance, develop more sensitive diagnostic methods and create a cheap test to detect TB in developing countries.

Emma Marris, Washington DC

\section{Deep-sea creatures yield treasure trove of cancer drugs}

An expedition to the Republic of Palau in Micronesia has led to the discovery that microbes inside a bright green creature that lives in tropical oceans produce peptides that can kill cancer cells.

Oceans are thought to be home to a treasure trove of chemicals that could be developed into drugs to treat debilitating illnesses such as cancer, chronic pain and arthritis.

The sea squirt Lissoclinum patella is a tunicate-meaning that it has a thick secreted covering like a tunic - that clings to rocks, piers and boats, and lives on the bottom of the sea. Scientists had previously found that ground-up extracts of these sea squirts have antitumor activity. University of Utah researchers have now discovered that the squirts are home to Prochloron didemni, a symbiotic bacteria that produce patellamides, small cyclic peptides consisting of eight amino acids that are toxic to human cancer cell lines.

In collaboration with researchers from The Institute for Genomic Research in Maryland, the scientists cloned the genes for patellamides and expressed them in Escherichia coli (Proc.
Natl. Acad.Sci. USA 102, 7051-7052; 2005). The method allows for a renewable supply of the compound, and for engineering more effective genetic variants.

"You don't have to take animals off relatively fragile coral reefs because you could potentially have all the compounds you need generated in culture in your lab," says lead investigator Eric Schmidt. He says he will continue his quest worldwide, including the Red Sea in Egypt and Papua New Guinea.

The finding is proof that marine organisms can be harnessed for drug discovery, says Tadeusz Molinski, professor of chemistry at the University of California, Davis. "It may also be the turning point in commercializing the potential of marine natural products."

Marine organisms may make some of these chemicals to protect themselves from predators and ward off other organisms. "In other cases, it may be a total coincidence that, say, a peptide that is used by a marine snail for hunting prey also can be used to kill pain in human patients," Molinski says.

According to a Natural Resources Defense

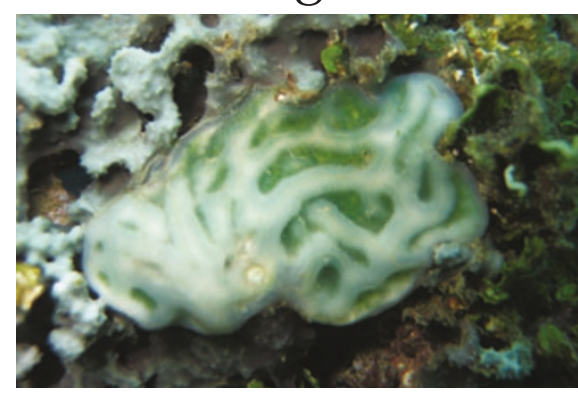

Digging deep: Sea squirts, which live on the ocean floor, harbor chemicals toxic to cancer cells.

Council report in March, more than 28 marine products are being tested in clinical trials, and many more are in preclinical development.

Most research has focused on creatures that dwell in shallow and tropical ocean water, but attention is increasingly being focused on the deep sea, where organisms have adapted over thousands of years to survive in cold, dark and highly pressurized places. "Three-quarters of the world is covered by oceans," Molinksi says. "We've only dipped below the surface."

Leslie Harris O'Hanlon, Placitas, New Mexico 